\title{
Holistic approach for biogas technology implementation to improve sustainability
}

\author{
Vidyarani S. Kshirsagar ${ }^{1}$, Prashant M. Pawar ${ }^{1}$ and Sayaji T. Mehetre ${ }^{2}$ \\ ${ }^{1}$ Department of Civil Engineering, SVERI's College of Engineering, Pandharpur 413 304, India \\ ${ }^{2}$ Nuclear Agriculture and Biotechnology Division, Bhabha Atomic Research Center, Mumbai 400085 , India
}

The sustainability of a technology can be improved by using a holistic approach. In this study, one such approach of implementation is demonstrated using the example of biogas technology. This case study is presented based on implementation experience of biogas technology in an academic campus located in a rural area in India. Though this is a well-known technology, it has not yet become sustainable due to various issues. Components of biogas technology can be categorized into three subgroups as preprocessing, main digester and post-processing. In the preprocessing phase, it is important to consider easily available feeds and their preprocessing to improve the performance of the anaerobic process. The improved design of a preprocessor helps in adopting various types of feeds available resulting into solid waste management. The performance of anaerobic process in the main digester is governed by the design of the digester, standard operating practices and maintenance processes. The appropriate consideration and implementation of these three parameters help in improving the gas production rate and fault tolerance. In the postprocessing phase, biogas and biogas manure need to be processed effectively for economic benefits from the biogas plant. These three processes of biogas technology are considered through holistic approach to improve collective performance and acceptability of the plant. The approach looks into modifications in the existing processes to serve other purposes like solid waste management, improvement in usage of biogas and manure along with inclusion of allied technologies to improve acceptability. Further, design modifications in the main digester are carried out through CFD analysis to improve velocity patterns in the digester with the objective of minimizing the biological faults and maximizing the mixing performance. This study shows how the holistic approach can bring together various interdependent components of a technology for simultaneous modifications.

Keywords: Biogas technology, holistic approach, solid waste management, sustainability.

SUSTAINABILITY of a technology can be improved by considering the technology from multi-functioning and

*For correspondence. (e-mail: pawarpm@sveri.ac.in) multi-objectivity point of view. This can be achieved by introducing various relevant technologies and modifications connected to the main technology so as to utilize the various benefits generated from it. Solid waste management is becoming a critical issue with growing urban population. The United Nations Conference on Environment and Development, held at Rio de Janeiro, Brazil, in June 1992, focused world attention on municipal solid waste issue along with other environmental problems ${ }^{1}$. The availability of landfill sites is declining due to conventional disposal methods, and opening of new landfill sites is limited due to financial and legal problems. Solid waste has heterogeneous characteristics and includes agricultural waste, municipal waste, domestic waste, animal waste, food waste, paper waste, plastic waste, etc. The typical solid waste analysis data ${ }^{2}$ in Figure 1, shows that food waste is a major component of solid waste.

Food waste management is an equally critical task under solid waste management. It is a biodegradable waste and has to be disposed of properly to avoid environmental consequences. Anaerobic digestion is a promising technology for food waste disposal and yields highest gas production compared to any other waste inputs $^{3}$. The experiments performed by El-Mashad and Zhang ${ }^{4}$ show the highest gas yield with food waste compared to unscreened dairy manure.

The present status, challenges and potential of biogas technology are highlighted by Surendra et $a l^{5}$, who have provided details about the potential economic, health, social and environmental merits of the biogas technology. As a part of CILLAGE project ${ }^{6}$, biogas technology deployment was performed using a holistic approach with various modifications in the existing technology and with inclusion of allied technologies (Figure 2).

Biogas technology was modified by introducing a predigester to improve the performance of the main digester for food waste input ${ }^{7}$. Another important aspect in the preprocessing phase includes selection of appropriate feeds. This selection may be from the solid waste management point of view, or for improving gas yield. The main biogas technology should be implemented appropriately by considering cause-effect analysis for minimizing the failures. Sometimes the plant or process can be modified for improving plant performance and fault tolerance. The post-processing phase of a biogas plant is 


\section{RESEARCH ARTICLES}

an important aspect which will help in improving economical viability. Therefore, it is important to not only focus on biogas, but also utilize various other by-products of the plant. Biogas can either be directly used for heating or cooking, or it can be scrubbed to increase the calorific value. The scrubbing process will throw out about 30 $40 \%$ carbon dioxide which can be utilized for improving soil health as carbonated water. The importance of soil organic carbon is brought out with another technology of portable soil organic carbon test kit. This technology helped in demonstrating improvement in soil organic carbon due to the use of biogas manure as organic fertilizer. Further, laboratory-level experiments and simulations are also performed to improve the acceptability of biogas technology.

\section{Holistic approach to biogas technology}

Various aspects of biogas technology can be grouped as preprocessing, main digester and post-processing (Figure 3).

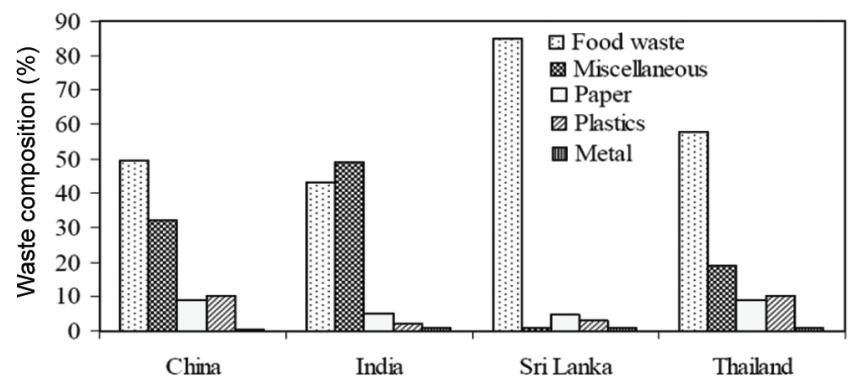

Figure 1. Municipal solid waste composition in selected Asian countries $^{2}$.

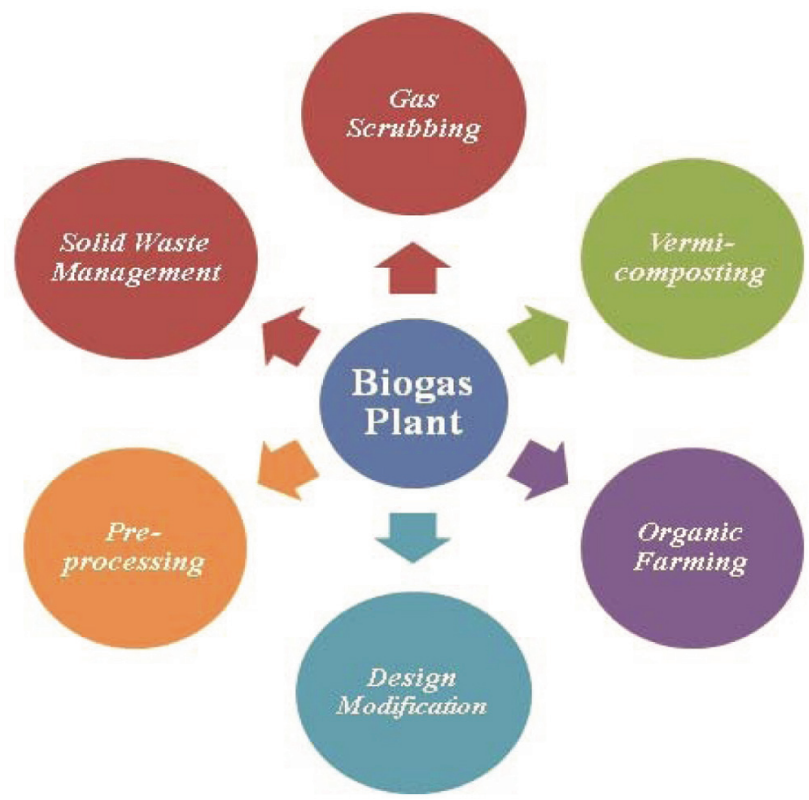

Figure 2. Holistic approach for biogas technology implementation.

\section{Preprocessing}

As shown in Figure 3, in the preprocessing phase focus is given on installing the pre-digester and studying the performance of the plant with various local solid waste inputs along with preprocessing. The purpose of the pre-digester is to utilize aerobic decomposition through fermentation and acidification of food waste which reduces burden on the anaerobic process in the main digester. The food waste is supplied by crushing it into fine particles to improve the rate of decomposition. The influence of particle size on improvement of gas production rate has already been demonstrated ${ }^{8}$. Preprocessing plays an important role in reducing the time required for decomposition in the main digester. The flower waste generated from the famous Vithoba Temple at Pandharpur was used to demonstrate solid waste management of local produce. Cow dung from farmer's farm in the vicinity was collected as a feed for biogas plant and biogas manure was returned to the farmers as a organic fertilizer. The aerobic decomposition rate is faster than the anaerobic decomposition rate and hence the air compressor was arranged in the pre-digester which will provide air in the pre-digester plant for the period of $1 \mathrm{~h}$ daily.

\section{Main processing}

The main digester was constructed with an inlet-outlet arrangement, floating dome with $35 \mathrm{~m}^{3}$ capacity, three compartments prepared with vertical baffles and the gas outlet unit. The main digester is an important unit where anaerobic decomposition of predigested material is performed with the help of methanogenic bacteria. The methanogenic bacteria decompose waste in the main digester and produce biogas along with manure as a by-product. The hot water added in the preprocessing step helps maintain the thermophylic condition in the main digester. The growth of thermophiles in the digester is assured by mixing the waste with hot water and maintaining the temperature in the range $55-60^{\circ} \mathrm{C}$. The solar water heating technology is utilized to minimize the expenses of water heating.

Mixing is an important aspect in the main digester for increasing gas production rate. The low mixing will not only reduces the gas production rate but also form a scum on the surface of the digester. The scum is a hard layer of non-degraded material accumulated at the surface which creates a hurdle in the release of biogas in the gas holder ${ }^{9}$. The biological process failure repairing is a tedious job where the entire digester has to be opened up and the process needs to be restarted right from culture formation. The whole repair process may take 2-3 months. Therefore, efforts are being made to minimize this fault using mechanical mixing. However, the impellers used in the process have several disadvantages such as sudden breakdown, energy consumption and corrosion, etc. As 

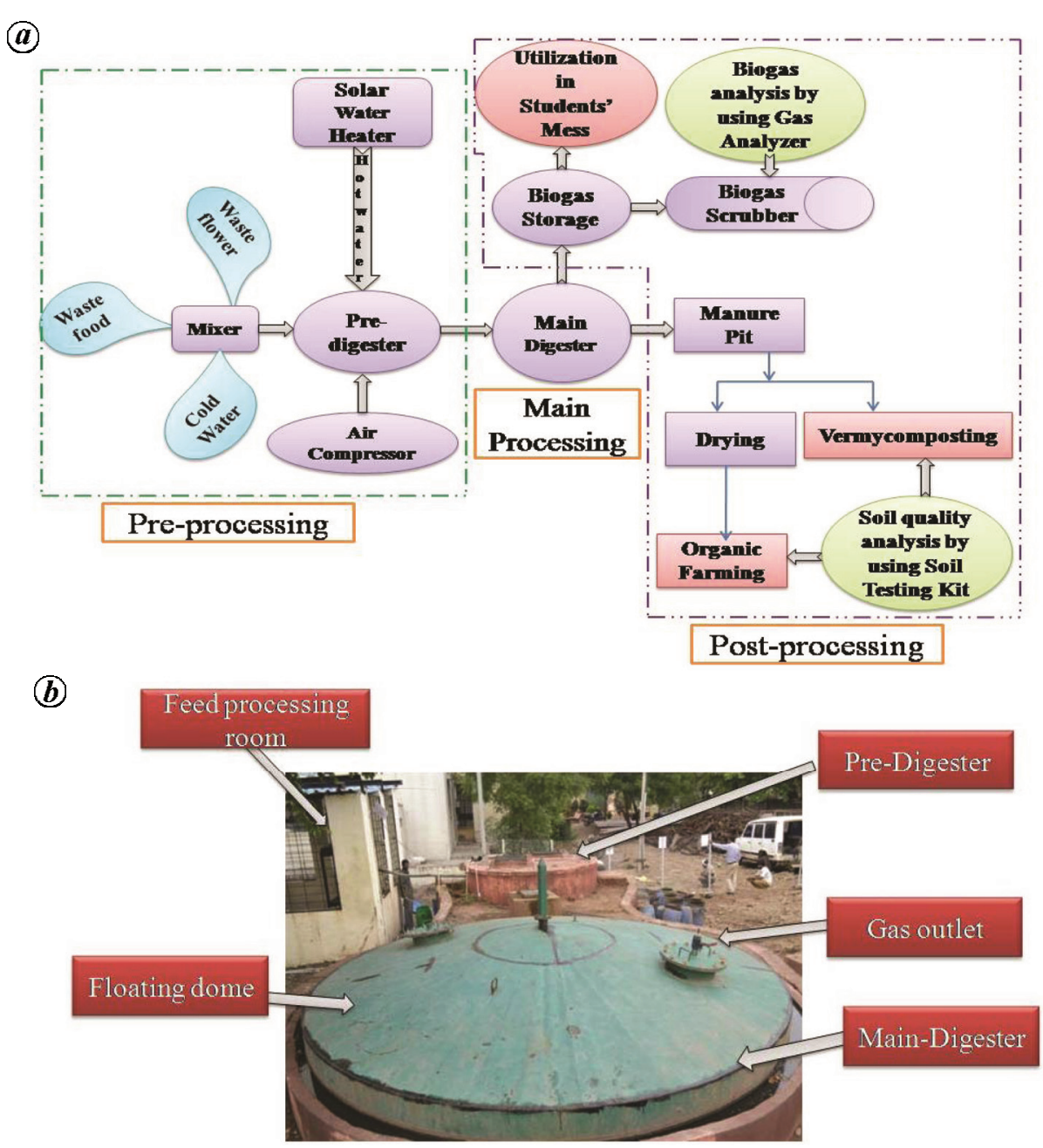

Figure 3. Complete framework of a biogas plant. $\boldsymbol{a}$, Schematic diagram; $\boldsymbol{b}$, actual plant.

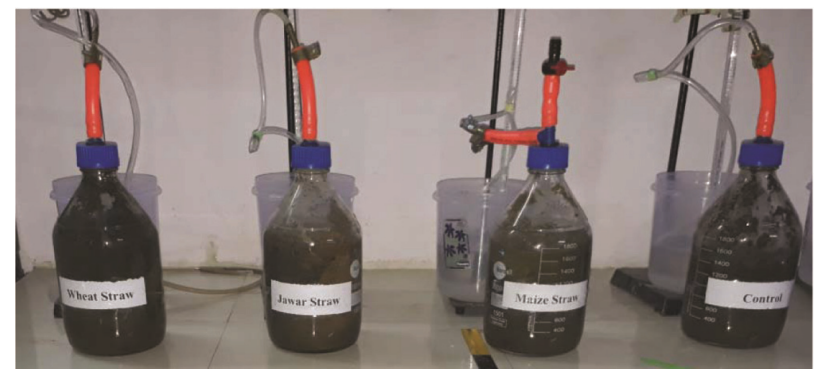

Figure 4. Feed proportionate study on lab-scale model.

part of holistic improvement of biogas technology, a computational fluid dynamic (CFD) simulation-based main digester design modification study was carried out to improve the mixing performance and fault tolerance. Three passive flaps were added to the existing digester. The velocity in the digester was considered as a mixing parameter. The numerical results show that the mixing performance increases drastically in the modified digester. Further, laboratory-level study using the set-up shown in Figure 4 was carried out to choose feed compo- sition for improving gas production rate. From the experimental results, it has been observed that the gas production rate is highly dependent on feed composition. The variation in feed composition is nothing but variation in starch composition which is the main component governing the gas production rate.

\section{Post-processing}

Typical biogas is a mixture of $50-70 \% \mathrm{CH}_{4}, 30-40 \% \mathrm{CO}_{2}$, and other types of gases, including ammonia, hydrogen sulphide and noxious gases. It is also saturated with water vapour. The gas composition varies based on of feed and other operating conditions of the plant. Biogas is generally used directly for cooking purposes in case of small-scale plants. Scrubbing helps in improving the calorific value of gas and removes hazardous gases. Recently, this scrubbing process has been linked with the improvement of soil organic carbon using carbonated water.

In the traditional method of scrubbing to remove carbon dioxide, biogas is passed through alkaline solution, 


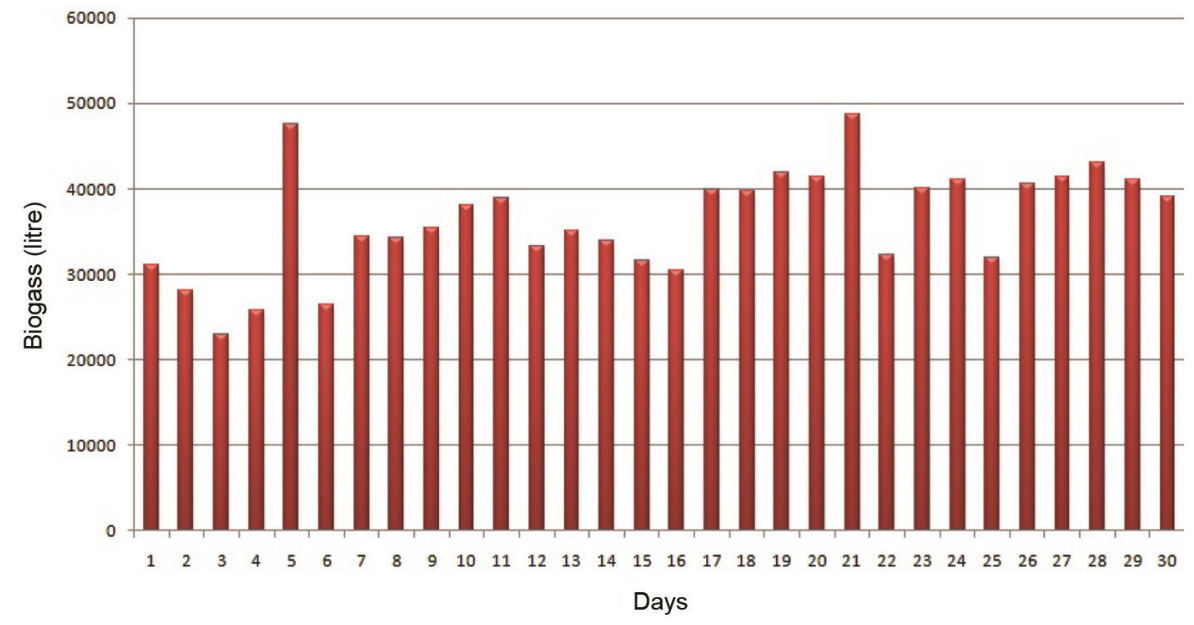

Figure 5. Biogas production.

Table 1. Impact of Nisargruna manure on soil in the form of organic carbon content

\begin{tabular}{|c|c|c|c|c|}
\hline \multirow[b]{2}{*}{ Name of farmer } & \multicolumn{4}{|c|}{ Month-wise organic carbon testing results } \\
\hline & June & August & October & December \\
\hline Hirabai Shankar Pawar & Low & Low & Medium & Medium \\
\hline Devidas Phule & Low & Medium & Medium & Medium \\
\hline Dinesh Jadhav & Medium & Medium & Medium & Medium \\
\hline Gajendra Bhagawan Shinde & Low & Medium & Medium & Medium \\
\hline Kiran Pawar-Patil & Sufficient & Sufficient & Sufficient & Sufficient \\
\hline Popat Shankar Pawar & Low & Medium & Medium & Medium \\
\hline Sanjay Phule & Low & Medium & Medium & Medium \\
\hline Tanaji Baba Gurav & Medium & Medium & Sufficient & Sufficient \\
\hline Dada Dattu Sawant & Medium & Medium & Sufficient & Sufficient \\
\hline
\end{tabular}

Low: less than $0.5 \%$; Medium: between $0.5 \%$ and $1 \%$; Sufficient: more than $1 \%$.

usually lime water. The improved scrubbing process of removing $\mathrm{CO}_{2}$ by exposing the biogas to water in vertical water towers helps in utilizing $\mathrm{CO}_{2}$ to make carbonated water. The present study does not focus on detailed analysis of the same, but the literature indicates the advantages of utilizing carbonated water for improving crop yield ${ }^{10}$.

The post-processing phase also involves appropriate utilization of biogas manure generated from the biogas plant. It was noticed during implementation of this technology, that the farmers generally used the cow dung directly as an organic fertilizer. To promote the utilization of biogas manure, another technology of soil organic carbon testing kit has been introduced. Soil organic carbon is essential for improving the process of providing micronutrients to the crops resulting into improvement in yield. Another advantage of improved soil organic carbon is the increase in biological control of plant diseases and pests. It also helps in providing fertilizers to reach the plant roots. The combined use of biogas technology with soil organic carbon testing kit helped in bringing about awareness among farmers to utilize biogas manure as an organic fertilizer.
The utility of biogas manure may be further improved by using vermicompost technology which will enhance the properties of biogas technology. A comparative study between cow dung and vermicompost showed the advantages of vermicomposting in terms of germination of seeds, root length, shoot length, number of root hairs, numbers of leaves, etc. ${ }^{11}$.

\section{Implementation results}

This section gives a brief description about combined implementation of various technologies aligned with biogas technology to improve its sustainability.

\section{Plant feed and biogas production}

One of the important aspects about making the plant sustainable is to utilize it for solid waste management in the region. The present holistic approach is demonstrated in an academic institute (SVERI) catering to about 5000 population, of which about $50 \%$ is residential. The biogas technology helped in managing food waste of about 


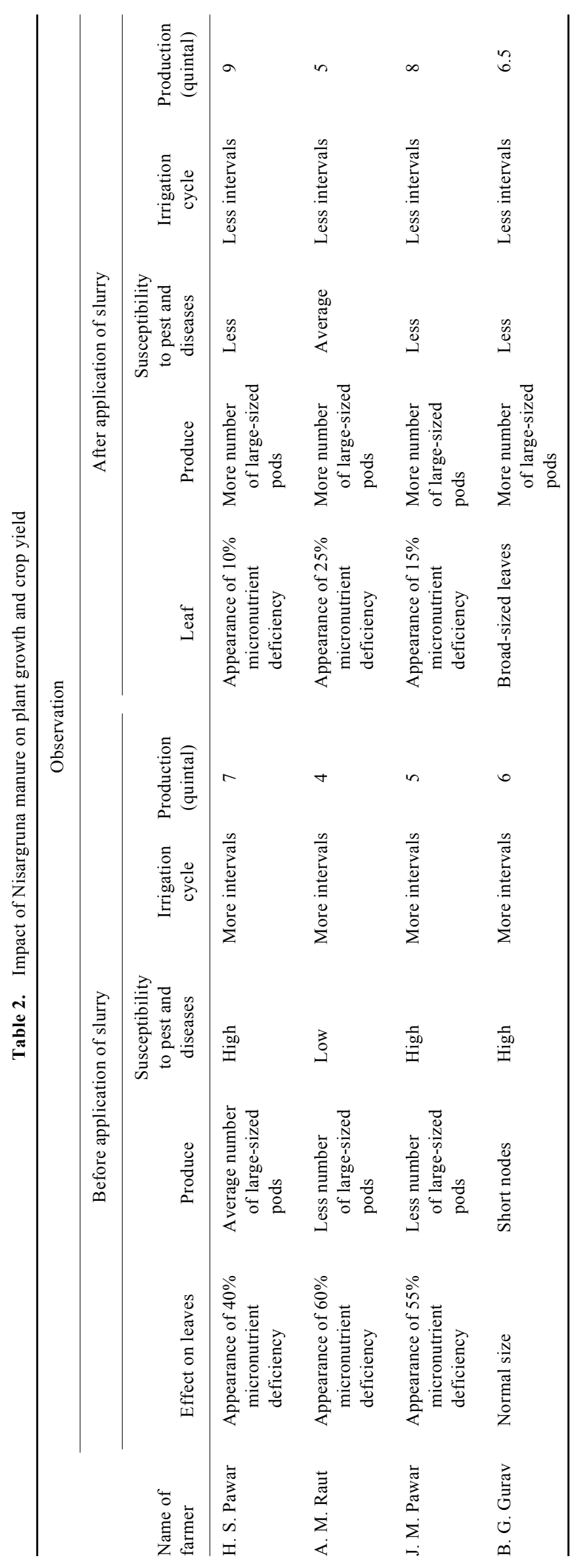



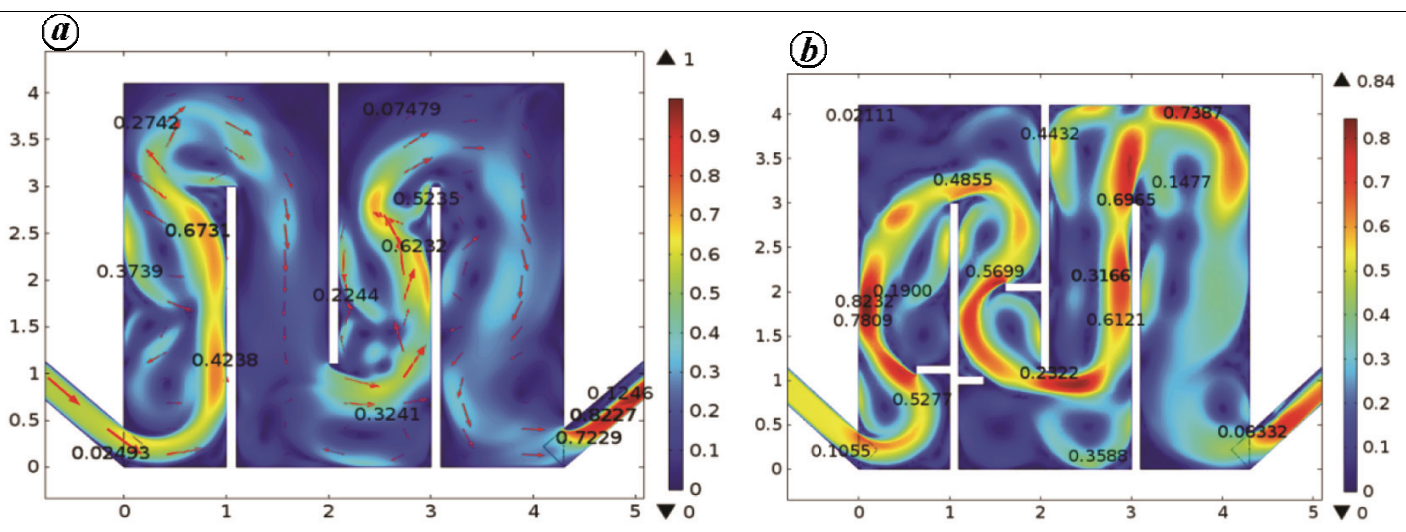

Figure 6. Velocity performance in ( $\boldsymbol{a})$ baseline biogas digester and $(\boldsymbol{b})$ modified biogas digester.
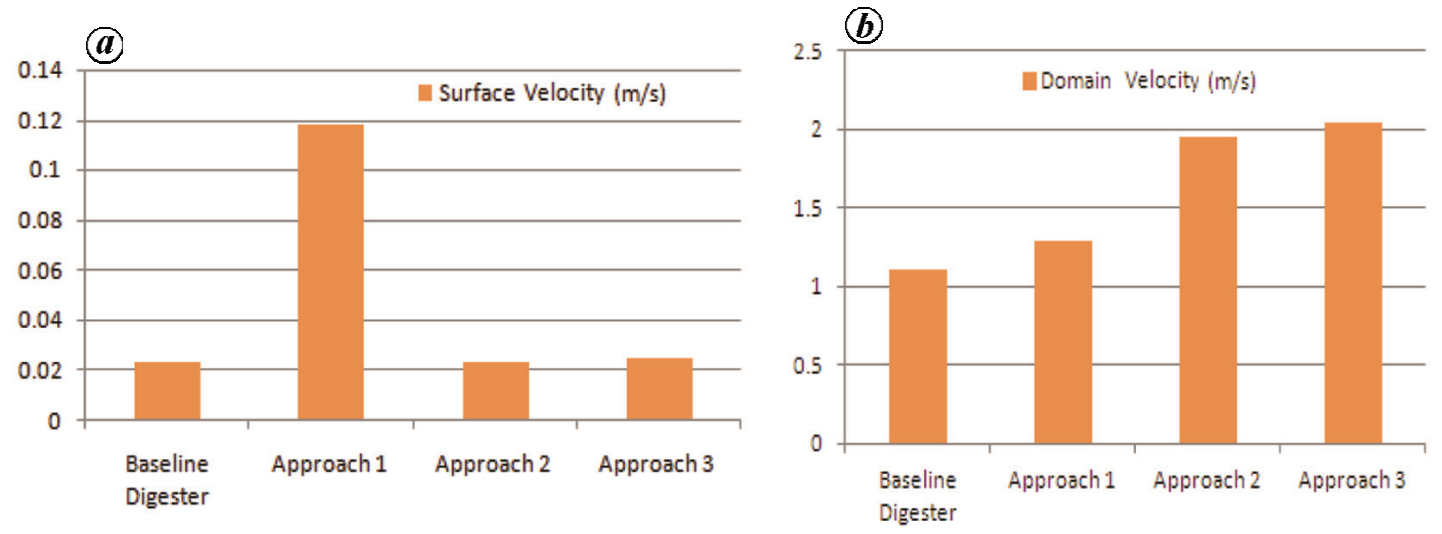

Figure 7. Velocity profile in (a) baseline biogas digester and (b) modified biogas digester.

$200-300 \mathrm{~kg}$ per day. To increase the feed and promote utilization of biogas manure to encourage organic farming, few farmers in the vicinity have been involved to supply about 400-500 kg cow dung per day.

Few experiments were also conducted by flower waste from the Vithoba Temple as feed. The gas produced was utilized in the institute canteen which generates the labour, local transport and other maintenance costs of the plant. Cow dung was exchanged with biogas manure and the impact of manure was periodically studied using soil organic carbon testing kit. These processes and the plant have been in operation from December 2014. Figure 5 shows the typical biogas production in November 2015.

\section{Biogas manure utilization for soil quality improvement}

Awareness was created among the farmers about the use and benefits of biogas manure or slurry as a fertilizer. Table 1 shows the impact results of biogas manure on soil in the form of organic carbon content. To observe the impacts of biogas slurry on crops, four plots were selected. The organic carbon content of soil was tested in the field for the sample before and after application of manure. The organic carbon testing kit designed in the SVERI campus with technology transferred from BARC, Mumbai was used for testing of soil to check the impact of manure on soil organic carbon quantity. Application of manure was started in May 2015 and changes in soil quality were continuously monitored for seven months. The result shows that soil organic carbon content is improved in all the plots. Along with this, impact of manure on plant growth and yield was also noted (Table 2).

\section{New innovations in the study of feed and design}

As shown in Figure 6, the baseline digester was modified by introducing three horizontal flaps. Numerical analysis was performed using CFD-based software COMSOL Multiphysics. Optimization was performed to obtain the optimal size and location of the three flaps using three different approaches: maximization of surface velocity (approach 1), maximization of domain velocity (approach 2 ) and maximization of combined (surface and domain) velocity (approach 3). Figure 6 shows the changed velocity patterns due to modifications. Figure 7 provides a summary of maximum surface and domain velocities for the optimal designs obtained by the three approaches. 


\section{Conclusion}

In this study, the use of holistic approach for technology deployment is demonstrated with the example of biogas technology. The implementation results of biogas technology along with various modifications in preprocessing, main digester and post-processing and implications about improving acceptability are discussed. The modifications of introducing the pre-digester have improved the capability of the plant to take various feeds and in reducing biological faults. The other allied technologies such as biogas scrubbing-based carbonation, soil organic carbon testing kit and vermicomposting have helped in improving the acceptability of the main technology. The acceptability of usage of biogas manure has been improved by demonstrating the improvement of soil organic carbon using the portable soil testing kit technology. Similarly, the value-addition process of scrubbing resulted into carbonated water which has become another value-added by-product to improve soil organic carbon. Further, experiments and simulations have been carried out to improve the main digester performance by reduction in scum formation and increase in mixing performance.

1. Beede, D. N. and Bloom, D. E., Economics of the generation and management of municipal solid waste. The National Bureau of Economic Research Working, 1995, Paper series no. 5116, p. 96.

2. Visvanathan, C., Trankler, J., Joseph, K., Chiemchaisri, C., Basnayake, B. F. A. and Gongming, Z., Municipal Solid Waste Management in Asia: Asian Regional Research Program on Environmental Technology (ARRPET), Asian Institute of Technology Publication, 2004, ISBN: 974-417-258-1.
3. Liu, C., Li, H., Zhang, Y. and Liu, C., Improve biogas production from low-organic-content sludge through high-solids anaerobic co-digestion with food waste. Bioresour. Technol., 2016, 219, 252-260.

4. El-Mashad, H. M. and Zhang, R., Biogas production from codigestion of dairy manure and food waste. Bioresour. Technol., 2010, 101, 4021-4028.

5. Surendra, K. C., Takara, D., Hashimoto, A. G. and Khanal, S. K., Biogas as a sustainable energy source for developing countries: opportunities and challenges. Renew. Sustain. Energy Rev., 2014, 31, 846-859.

6. Kakodkar, A., Ronge, B., Patankar, A., Mule, S. and Pawar, P., A concept of knowledge and technology enabled empowerment of rural Indian villages. Curr. Sci., 2017, 112(4), 750-758.

7. Kale, S. P. and Mehetre, S. T., Biogas plant based on kitchen waste. Nucl. India, 2002, 36(5), 9

8. Izumi, K., Okishio, Y., Nagao, N., Niwa, C., Yamamoto, S. and Toda, T., Effects of particle size on anaerobic digestion of food waste. Int. Biodeterior. Biodegr., 2010, 64, 601-608.

9. Cheng, S., Li, Z., Mang, H.-P., Neupane, K., Wauthelet, M. and Huba, E.-M., Application of fault tree approach for technical assessment of small-sized biogas systems in Nepal. Appl. Energy, 2014, 113, 1372-1381.

10. Storlie, C. A. and Heckman, J. R., Bell pepper yield response to carbonated irrigation water. J. Plant Nutr., 2008, 19, 1477-1484.

11. Rajeshkumar, K. T. and Ravichandran, C., Vermicomposting of biogas plant slurry and cow dung with Eudrilus eugeniae and its effects on Vigna radiate. Pelagia Res. Lib. Adv. Appl. Sci. Res., 2015, 6(7), 159-164.

ACKNOWLEDGEMENT. This research was partially funded by the Rajiv Gandhi Science and Technology Commission, Government of Maharashtra, Mumbai.

Received 13 May 2017; accepted 25 October 2018

doi: $10.18520 / \mathrm{cs} / \mathrm{v} 116 / \mathrm{i} 2 / 249-255$ 